Hồng Thinh, (2013), "Tân suất rối loan cương ở những bệnh nhân nam bị bướu lành tuyến tiền liệt trước khi cắt đốt nôii soi tuyến tiền liêt qua ngả niệu đạo", Tap chí Y học TP Hồ Chí Minh, 3 tr. 345-350.

2. Amel Kardasevic, Snjezana Mílicevic, (2017), "Correlation of Subjective Symptoms in Patients with Benign Prostatic Hyperplasia and Erectile Dysfunction", Pubmed, 71(1) pp. 32-36.

3. Giovanni Corona, Linda Vignozzi, Giulia Ratrelli, Francesco Lotti, et al, (2014), "Benign Prostatic Hyperplasia: A New Metabolic Disease of the Aging Male and Its Correlation with Sexual Dysfunctions", Pubmed, 2014 pp. 1-14.

4. Sidney Glina, Felipe Placco Araujo Glina, (2013), "Pathogenic mechanisms linking benign prostatic hyperplasia, lower urinary tract symptoms and erectile dysfunction", Pubmed, 5(4) pp. 211-218.

5. John P. Mulhall, Xuemei Luo, Kelly H. Zou,
(2016), "Relationship between age and erectile dysfunction diagnosis or treatment using realworld observational data in the United States", Pubmed, 70(12) pp. 1012-1018.

6. Lei Wang, Tongqing Wang, Jian Liu, Jizheng Wang, (2018), "Correlation Analysis of Erectile Dysfunction with Lower Urinary Tract Symptoms (LUTS) Degree and Clinical Features in LUTS Patients", Pubmed, 47(5) pp. 658-665.

7. Michael Ng, Krishna M. Baradhi, (2020), "Benign Prostatic Hyperplasia", Pubmed.

8. Qiang Shao, Jian Song, Yu-wen Gou, Wencheng Lu, et al, (2005), "Evaluation of sexual function in men with symptomatic benign prostatic hyperplasia", Pubmed, 11(7) pp. 505-507.

9. Reginald C Bruskewitz, (2003), "Quality of Life and Sexual Function in Patients with Benign Prostatic Hyperplasia", Pubmed, 5(2) pp. 72-80.

\title{
RỐI LOẠN NHIỄM SẮC THỂ Ở THAI PHỤ CÓ KẾT QUẢ SÀNG LỌC NGUY CO' CAO TẠI BỆNH VIỆN PHỤ SẢN TRUNG ƯO'NG
}

\section{TÓM TẮT}

Mục tiêu: xác định tỷ lệ rối loạn nhiễm sắc thể ở thai phu có kết quả sàng loc nguy cơ cao bằng xét nghiệm double test ở tuổi thai 12 tuân tại Bệnh viện Phụ sản Trung ương, năm 2019-2020. Kểt quả: Tuổi trung bình của thai phụ nguy cơ cao là $38,45 \pm 5,87$. Đô tuổi thai phu găp nhiều nhất trong nghiên cứu là $>37,5$ tuổi, chiểm 70,7\%. Khoảng sáng sau gáytrong nghiên cứu đa số trong khoảng $<2,5 \mathrm{~mm}$, chiếm $80,9 \%$. Từ $2,5-3 \mathrm{~mm}$ chiếm $9,8 \%$. Từ $3 \mathrm{~mm}$ trở lên chiếm 9,3\%.Thai bất thường NST chiếm 13/225 = $5,8 \%$. Trong số các thai có bất thường NST, thì thai hội chứng Down chiếm tỷ lệ cao nhất với 13/225 = $5,8 \%$. Không có trường hợp nào mắc hội chứng Edwards và hội chứng Patau. Kết luân: ở thai phu có kết quả sàng lọc nguy cơ cao có tỷ lệ bất thường nhiễm sắc thể cao $(5,8 \%)$, trong đó tất cả các trường hơp là thai hôi chứng Down.

Tư khoá: sàng lọc trước sinh, rối loạn nhiễm sắc thể, hội chứng Down

\section{SUMMARY \\ THE CHROMOSOMAL ABNORMALTTY IN HIGH- RISK PREGNANCY AT THE NATIONAL HOSPITAL OF OBSTETRICS AND GYNECOLOGY \\ Objectives: to determine the prevalence of chromosomal abnormality in double test high-risk result at 12 weeks pregnancy at the National Hospital of Obstetrics and Gynecology between 2019 and \\ *Bộ môn Phụ sản - Trường Đại học Y Hà Nội Chịu trách nhiệm chính: Nguyễn Mạnh Thắng Email: bsnguyenmanhthang@gmail.com Ngày nhận bài: 12.3.2021 \\ Ngày phản biện khoa học: 11.5.2021 \\ Ngày duyệt bài: 18.5.2021}

\section{Nguyễn Mạnh Thắng*}

2020. Results: The average age of high-risk pregnant women was $38,45 \pm 5,87$; of which $70,7 \%$ was over 37,5 years old. In this study, the nuchal traslucency was mostly $<2.5 \mathrm{~mm}$, accounting for $80.9 \%$; meanwhile, nuchal traslucency $2,5-3 \mathrm{~mm}$ and $>3 \mathrm{~mm}$ accounted for $9,8 \%$ and $9,3 \%$ respectively. The rate of fetus with chromosomal abnormalities was 13/225 $(5,8 \%)$. In these fetuses, Down's syndrome had the highest rate with $13 / 225(5,8 \%)$. No Edwards' syndrome and Patau's syndrome were detected in our study. Conclusions: High-risk pregnant women had a high prevalence of chromosomal abnormality $(5,8 \%)$, all cases of chromosomal abnormality were Down's syndrome.

Key words; prenatal screening, chromosomal abnormality, Down's syndrome.

\section{I. ĐăT VẤN ĐỀ}

Sinh ra một đứa trẻ khoẻ mạnh là mong ước của gia đình và toàn xã hội, giảm tî lệ dị tật bẩm sinh ở trẻ là nhiệm vụ của ngành sản phụ khoa. Với sự tiến bộ của y học, xét nghiệm sàng lọc, chẩn đoán trước sinh đã được nghiên cứu ứng dụng để sàng lọc, chẩn đoán sớm những bẫt thường của thai nhi từ đó tî lệ trẻ dị tật bẩm sinh ngày càng giảm [1]. Trong các bất thường bẩm sinh thì hiện tại bất thường nhiễm sắc thể (NST) vẫn là một vấn đề lớn nhận được nhiều sự quan tâm trong ngành sản phụ khoa thế giới nói chung và ở Việt Nam nói riêng do những biểu hiện nặng nề đặc biệt là đa dị tật về hình thái, chậm phát triển về trí tuệ và không có biện pháp điều trị đặc hiệu. Trên thế giới các chương trình sàng lọc chẩn đoán trước sinh đã và đang được 
phát triển manh mẽ nhằm chẩn đoán sớm các trường hợp bất thường nhiễm sắc thể. Để xác định các nguyên nhân di truyền gây ra dị tật bẩm sinh cho thai nhi cần phải có các tế bào có nguồn gốc từ thai như: tế bào tua rau hoặc tế bào ối... nhưng để lấy được những tế bào này hầu hết đều sử dụng các kỹ thuật có xâm phạm đến thai nhi, có thể gây rủi ro cho mẹ và thai như: nhiễm trùng, sây thai, rỉ ối... Các bất thường NST chiếm tỉ lệ $0,1-0,2 \%$ tổng số trẻ sinh hàng năm [2]. Trong số các bất thường NST, hay gặp nhất là bất thường NST 21 gây ra Hội chứng Down (53\%), tiếp đó là hội chứng Edward (3 NST 18) chiếm tỉ lệ 13\%, hội chứng Turner (1 NST X) chiếm tỉ lệ $8 \%$, hội chứng Patau (3 NST 13) chiếm tỉ lệ 5\% [3]. Nghiên cứu được tiến hành với mục tiểu: xác định tỷ lệ rôi loạn nhiễm sắc thể ở thai phụ có kêt quả sàng lọ nguy cơ cao tại Bệnh viện Phụ sản Trung ương, năm 2019-2020.

\section{II. ĐỐI TƯỢNG VÀ PHƯƠNG PHÁP NGHIÊN CỨU}

2.1. Đối tượng nghiên cứu. Đối tượng nghiên cứu gồm các thai phụ có kết quả xét nghiệm sàng lọc bằng xét nghiệm double test ở tuổi thai 12 tuần có nguy cờ cao từ tháng 09/2019 đến tháng 03/2020 tại Bệnh viện Phụ sản Trung Ương.

*Tiêu chuẩn lựa chọn: Là những thai phụ đã tham gia nghiển cứu phù hợp những tiêu chuẩn sau: có một thai, thai sống. Tuổi thai từ 11 tuần - 13 tuần 6 ngày. Kết quả xét nghiệm sàng lọc nguy cơ cao và có kết quả chọc ối. Các thai phụ đồng ý tham gia nghiên cứu có đầy đủ thông tin hồ sơ bệnh án.

*Tiêu chuẩn loai trừ: Những thai phụ đã làm sàng lọc nhưng sau đó sẩy thai hoặc thai lưu, không rõ tình trạng nhiễm sắc thể.

\subsection{Phương pháp nghiên cứu}

2.2.1. Thiêt kế nghiên cứu: mô tả cắt ngang.

2.2.2. Cỡ mẫu nghiên cứu: gồm 225 thai phụ tham gia làm xét nghiệm sàng lọc phù hợp với tiêu chuẩn lựa chọn và tiêu chuẩn loại trừ'.

2.2.3. Các tiêu chuẩn đánh giá nghiên cứu: xét nghiệm double test ở tuổi thai 12 tuần áp dụng tại trung tâm chẩn đoán trước sinh bệnh viện Phụ Sản Trung Ương

- Dương tính: thai thuộc nhóm nguy cơ cao có bất thường NST (hội chứng Down, hội chứng Edwards, hội chứng Patau).

- Thai thuộc nhóm nguy cơ cao khi nằm trong các ngưỡng sau:

+ Hội chứng Down theo sinh hóa $\geq 1 / 320$.

+ Hội chứng Edwards $\geq 1 / 100$.
+ Hội chứng Patau $\geq 1 / 100$.

- Âm tính (nguy cơ thấp): quy định kết quả nhỏ hơn ngưỡng nguy cơ dương tính.

2.2.4. Phương pháp xét nghiệm NST: Bênh phẩm từ thủ thuât chọc ối ở tuổi thai 16 tuân sẽ được làm một hoặc nhiêu hơn một trong các phương pháp dưới đây để xác định bất thường NTS.

- Nuôi cấy tế bào và lập karyotyp.

- Phương pháp di truyền phân tử: áp dụng một hoặc và các phương pháp: QF-PCR (Quantiative Fluorescence - Polymerase chain reaction), Prenatal BoBs (Prenatal Bacs-on-Beads).

2.3. Xử lý số liệu: số liệu được nhập, quản lý và phân tích trên phần mềm thống kê SPSS 16. Số liệu được trình bày dưới dạng tần số và tỷ lệ phần trăm.

2.4. Đạo đức nghiên cứu: Các thông tin về thai phụ sẽ được giữ kín và chỉ được sử dụng cho mục đích nghiên cứu. Trong quá trình xử lý số liệu thông tin thai phụ được mã hóa, không tiết lộ danh tính. Không tiến hành bất cứ thử nghiệm lâm sàng hay cận lâm sàng nào trên thai phụ. Bệnh nhân được theo dõi sát trong quá trình làm test và tư vấn kết quả sau thử test.

\section{KẾT QUẢ NGHIÊN CỨU}

3.1. Đặc điểm của đối tượng nghiên cứu. Kết quả cho thấy độ tuổi thai phụ $>37,5$ tuổi chiếm $70,7 \%$, nhóm tuổi từ 35 đến 37,5 chiếm 4,9\%, nhóm <35 tuổi chiếm 24,4\%. Tuổi trung bình của thai phụ có kết quả Double test nguy cơ cao là $38,45 \pm 5,87$. Thai phụ nhỏ tuổi nhất là 20 tuổi, lớn tuổi nhất là 48 tuổi.Tuổi thai trong nhóm nghiên cứu là nhóm tuổi thai $<14$ tuân. Tuổi thai thấp nhất là 11 tuần 0 ngày, tuổi thai cao nhất là 13 tuần 6 ngày. Tuổi thai trung bình là 12 tuần 0 ngày \pm 3 ngày. Đa số thai phụ có tiền sử bệnh tật bình thường chiếm 99,11\%, 1 thai phụ có tiền sử Basedow đã điều trị, dừng thuốc trong thời kỳ có thai, 1 thai phụ bị mắc thủy đậu lúc mang thai 10 tuần, không có thai phụ nào bị đái tháo đường.

Bảng 1. Phân bố khoảng sáng sau gáy trong nghiên cứu

\begin{tabular}{|c|c|c|}
\hline Khoảng sáng sau gáy & $\mathbf{n}$ & Tỉ lệ $\%$ \\
\hline$<2,5 \mathrm{~mm}$ & 182 & 80,9 \\
\hline $2,5-3 \mathrm{~mm}$ & 22 & 9,8 \\
\hline$\geq 3 \mathrm{~mm}$ & 21 & 9,3 \\
\hline Tống & $\mathbf{2 2 5}$ & $\mathbf{1 0 0}$ \\
\hline
\end{tabular}

Nhận xét: Khoảng sáng sau gáytrong nghiên cứu đa số trong khoảng $<2,5 \mathrm{~mm}$, chiếm $80,9 \%$. Từ 2,5-3mm chiếm 9,8\%. Từ $3 \mathrm{~mm}$ trở lên chiếm $9,3 \%$. 
Bảng 2. Tỉ lệ thai có nguy cơ Down, Edward, Patau trong nhóm nguy co cao

\begin{tabular}{|c|c|c|c|}
\hline \multicolumn{2}{|c|}{ Nguy cơ dị tật } & n & Tỉ lệ $\%$ \\
\hline \multirow{2}{*}{ Down } & Cao & 225 & $100 \%$ \\
\cline { 2 - 4 } & Thấp & 0 & 0 \\
\hline \multirow{2}{*}{ Edward } & Cao & 1 & $0,44 \%$ \\
\cline { 2 - 4 } & Thấp & 224 & $99,56 \%$ \\
\hline \multirow{2}{*}{ Patau } & Cao & 2 & $0,89 \%$ \\
\cline { 2 - 4 } & Thấp & 223 & $99,11 \%$ \\
\hline
\end{tabular}

Nhận xét: Trong nhóm sàng lọc có nguy cơ cao, chủ yếu là thai có nguy cơ cao với Down, chiếm $100 \%$, có 1 trường hợp nguy cơ cao với 2 hội chứng Down và Patau, 1 trường hợp nguy cơ cao với cả 3 hội chứng hội chứng Down, Edward và Patau.

Bảng 3. Tỷ lệ các bất thường NST trong đôî tượng NCC

\begin{tabular}{|c|c|c|c|}
\hline Phân loại & $\begin{array}{c}\text { Loaai bất } \\
\text { thường NST }\end{array}$ & $\mathbf{n}$ & $\begin{array}{c}\text { Tỷ lệ } \\
(\%)\end{array}$ \\
\hline \multirow{3}{*}{$\begin{array}{c}\text { Thai bất } \\
\text { thường } \\
\text { NST }\end{array}$} & Thai HC Down & 13 & 5,8 \\
\cline { 2 - 4 } & $\begin{array}{c}\text { Thai HC } \\
\text { Edwards }\end{array}$ & 0 & 0 \\
\cline { 2 - 4 } & Thai HC Patau & 0 & 0 \\
\cline { 2 - 4 } & $\begin{array}{c}\text { Các bất } \\
\text { thường khác }\end{array}$ & 0 & 0 \\
\hline Thai bình thường & 212 & 94,2 \\
\hline \multicolumn{2}{|c|}{ Tống } & 225 & 100 \\
\hline \multirow{2}{*}{ Tốn }
\end{tabular}

Nhận xét: Thai bất thường NST chiếm $13 / 225=5,8 \%$. Trong số các thai có bất thường NST, thì thai $\mathrm{HC}$ Down chiếm tỷ lệ cao nhất với $13 / 225=5,8 \%$.

\section{BÀN LUẬN}

Trong số 225 thai phụ có kết quả sàng lọc nguy cơ cao, có 225 trường hợp có nguy cơ cao với $\mathrm{HC}$ Down, 1 trường hợp có nguy cơ cao với cả 3 hội chứng Down, Turner và Edwards, 1 trường hợp nguy cơ cao với hội chứng Down và Patau. Theo WHO (2008), DTBS chiếm 3 - 6\% số trẻ được sinh ra hàng năm, nhưng chắc chắn tỷ lệ DTBS ở thai sẽ cao hơn vì một số lượng lớn thai có DTBS nặng thì đã bị sảy hoặc chết lưu trước khi được sinh ra.Nghiên cứu của chúng tôi được tiến hành trên 225 thai phụ có NCC khi sàng lọc trong ba tháng đầu thai kỳ. Đa số các thai phụ trong nghiên cứu có kết quả chọc ối bình thường, 212 trong tổng số 225 thai phụ, phát hiên được 13 thai có bất thường NST các loại chiếm 5,8\% tổng số các đối tượng NCC. Trong đó cả 13 trường hợp đều là mắc hội chứng Down, không có trường hợp nào mắc hội chứng Edwards và hội chứng Patau.

Theo nghiên cứu năm 2013 tại TP Hồ Chí Minh, khi nghiên cứu kết quả chọc ối của 4.300 thai phụ thì tỷ lệ này là 6,16\% [4]. Tỷ lệ thai bất thường NST trong nghiên cứu của chúng tôi thấp hơn hai tác giả trên, tuy nhiên sự khác biệt này không có ý nghĩa thống kê với $p>0,05$.

Theo Phạm Tuấn Dũng (2015), khi nghiên cứu kết quả chọc ối của 2.256 thai phụ trong thời gian từ 2013 - 2014 thì tỷ lệ thai bất thường NST trong số các đối tượng nghiên cứu là 5,36\%. Còn theo Zhang L. và cộng sự (2010), nghiên cứu kết quả chẩn đoán trước sinh của 2.782 thai phụ trong thời gian từ 2004 - 2009 thu được tỷ lệ bất thường NST trong số các đối tượng nghiên cứu là 4,99\%. Tỷ lệ bất thường NST trong nghiên cứu của chúng tôi cao hơn trong nghiên cứu này tuy nhiên sự khác biệt này không có ý nghĩa thống kê với $p>0,05$.

Trong số 13 thai bất thường NST phát hiện được trong nghiên cứu của chúng tôi, thai $\mathrm{HC}$ Down chiếm số lượng nhiều nhất với cả 13 trường hợp tương đương với 5,8\% tổng số đối tượng NCC. Theo nghiên cứu của Nguyễn Thị Tuyết (2013) thì tỷ lệ này là $5,67 \%$. Như vậy tỷ lệ thai Down trong nghiên cứu của chúng tôi cao hơn trong nghiên cứu của tác giả Nguyễn Thị Tuyết tuy nhiên sự khác biệt này không có ý nghĩa thống kê với $p>0,05$. Như vậy, tỷ lệ thai bất thường NST và thai $\mathrm{HC}$ Down trong nghiên cứu của chúng tôi phù hợp với các nghiên cứu của các tác giả trước đây.

Hâuu hết những đứa trẻ mắc hội chứng Down đều chậm phát triển tinh thần như chậm đi, chậm nói, khả năng diễn đạt kém, chỉ số IQ trung bình 30-50. Ngoài ra những đứa trẻ mắc HC Down còn mắc các dị tật bẩm sinh khác như: tim bẩm sinh chiếm $40-60 \%$ các trường hợp (thông liên thất, thông liên nhĩ, thông sàn nhĩ thất, tứ chứng Fallot...), teo tá tràng chiếm $30 \%$ các trường hợp, dị tật hệ xương, giảm trương lực cơ, giãn não thất vứa (<15mm), leucemia... [5].

Bên cạnh những nguyên nhân do tác động môi trường, các bênh lý của người me như viêm gan virus, đái tháo đường, viêm tuyến giáp, thói quen uống rượu, hút thuốc, thì tuổi me có vai trò quan trọng: tî̀ lệ mắc hội chứng Down tăng nhanh theo tuổi me.

Mặc dù tỉ lệ mắc HC Down tăng nhanh theo tuổi mẹ, tuy nhiên cũng có nhiều nghiên cứu cho thấy tỉ lệ mắc hội chứng Down ở trẻ được sinh ra bởi những bà me quá trẻ cũng tương đối cao. Hơn nữa, thống kê cho thấy khoảng $80 \%$ số trẻ bị hội chứng Down được sinh ra từ những người phụ nữ dưới 35 tuổi [6]. Chính vì vậy mà sàng lọc và chẩn đoán trước sinh hội chứng Down cần được tiến hành ở tất cả các thai phụ.

Kết quả nghiên cứu của chúng tôi không ghi 
nhận trường hợp nào mắc hội chứng Edwards và hội chứng Patau. Theo các nghiên cứu, hội chứng Edwads là hội chứng bất thường nhiễm sắc thể 18 có tỉ lệ mắc là $1 / 3000$, thường gặp ở thai gái, tỉ lê 4 gái/1 trai [7]. Có $80 \%$ các trường hợp hội chứng Edwards là ba nhiễm sắc thể 18 thuần, $10 \%$ là thể khảm và $10 \%$ là do chuyển đoạn nhiễm sắc thể 18 [8]. Tần suất xuất hiện hội chứng Patau là $1 / 10000$, nguyên nhân do thừa 1 NST 13. 95\% các thai mắc hội chứng Patau sẽ thành thai lưu, chỉ $5 \%$ trường hợp được sinh ra, tuy nhiên trên $90 \%$ các trường hợp này sẽ tử vong trong năm đầu do các dị tật bẩm sinh nặng nề) [9].

\section{KẾT LUẬN}

Tuổi trung bình của thai phụ nguy cơ cao là $38,45 \pm 5,87$. Độ tuổi thai phụ gặp nhiêu nhất trong nghiên cứu là $>37,5$ tuổi, chiếm $70,7 \%$. Khoảng sáng sau gáy trong nghiên cứu đa số trong khoảng $<2,5 \mathrm{~mm}$, chiếm $80,9 \%$. Từ $2,5-$ $3 \mathrm{~mm}$ chiếm $9,8 \%$. Từ $3 \mathrm{~mm}$ trở lên chiếm 9,3\%.

Thai bất thường NST chiếm 13/225 = 5,8\%. Trong số các thai có bất thường NST, thì thai hội chứng Down chiếm tỷ lệ cao nhất với 13/225 = $5,8 \%$. Không có trường hợp nào mắc hội chứng Edwards và hội chứng Patau.

\section{TÀI LIÊU THAM KHẢO}

1. Waild, JN, Anne $K$, Allan $H$, Ali M. Antenatal screening Down's syndrome, Journal of screening. 1997; 4: 181- 246.

2. Dungan, Jeffrey S, Elias, Sherman Prenatal Diagnostic Testing. The Merck Manuals Online Medical Liary. Archived from the original on 4 August 2010. Retrieved July. 2008; 30: 2010.

3. ACOG committee on Practice Bulletins ACOG Practice Bulletins No. 77: Screening for fetal chromosal abnormalities. Obtest Gynecol. 2007; 109: 217- 227.

4. Phan Xuân Diêp, Pham Thi Mai. Sàng loc thai hội chứng Down tại khoa phụ sản bệnh viện Đại hoc Y dược thành phố Hồ Chí Minh từ 110/2009 đến tó/2012, Tạp chíy học thành phố Hồ Chí Minh, 5. 2012: 15-22.

5. Hoàng Thu Lan. Hoàn chỉnh kỹ thuât lai tai chỗ huỳnh quang trong chẩn đoán trước sinh hội chứng Down. Luân văn thac sĩ Y hoc, Hà Nôi. 2004.

6. Lê Thanh Thuý. Đ̇ánh giá kết quả chọc hút nước ối để phân tích NST phát hiện dị tật của thai nhi tai bênh viên phu sản Hà Nồi và phu sản trung ương, Luận văn tổt nghiệp bác sĩ chuyển khoa cấp 2, Hà Nội. 2009.

7. Sybert VP, Mc Cauley E. Turner's syndrome. N Engl J Med. 2004; 351 (12): 1227- 1238.

8. Tartaglia NR, Howell $S$, Surtherland $A$, Wilson $R$, Wilson $L$. A review of trisomy $X$ (47XXX) . Orphanet J Rare Dis. 2010; 5(1):8.

9. Park JH, et al. Effects of sex chromosome aneuploidy on male sexual behavior. Genes Brain Behav. 2008; 7(6): 609- 617.

\section{THƯC TRANG LOÉT ÁP LỰC VÀ MộT SỐ YẾU TỐ LIÊN QUAN ĐẾN NGƯỜI BỆNH HÔN MÊ TẠI KHOA HỒI SỨC TÍCH CỰC VÀ CHỐNG ĐộC BÊ̂NH VIÊ̂N ĐA KHOA TRUNG ƯO'NG CẦN THO'}

\section{TÓM TẮT}

Nghiên cứu mô tả tiến cứu thực hiên tai Khoa hồi sức tích cực và chống độc BV Đa Khoa Trung ương Cần Thơ từ tháng 10/2020 đến tháng 03/2021 trên 185 người bệnh hôn mê. Mục tiêu là (1) Mô tả đặc điểm lâm sàng, cân lâm sàng, tình trang loét của người bệnh hôn mề tại Khoa hồi sức tích cực và chống độc Bệnh viện Đa Khọa Trung ương Cần Thơ (2) Phân tích kết quả chăm sóc người bệnh và một số yếu tố liên quan. Kết quả cho thấy người bệnh hôn mê có số ngày nằm viện trung bình là: $8,48 \pm 1,61$, tỷ lệ người bệnh có loét chiếm $26,5 \%$, không loét $73,5 \%$, có một vết loét chiếm $32,4 \%$, có 2 vết loét chỉ có

${ }^{1}$ Bệnh viện $Đ K T W$ Cần Tho

${ }^{2}$ Trường ĐH Thăng Long

Chịu trách nhiệm chính: Trương Thanh Phong

Email: truongthanhphong5318@gmail.com

Ngày nhận bài: 15.3.2021

Ngày phản biên khoa hoc: 13.5.2021

Ngày duyệt bài: 20.5.2021

\section{Trương Thanh Phong1, Dương Thị Hòa ${ }^{2}$}

4,3\%, loét độ I chiếm 56,6\% và loét độ II là 43,4\%. Về hoạt động chăm sóc vết loét trong 7 ngày: $\leq$ 1lần/ngày chiếm tỷ lệ cao từ $84,3 \%$ đển $89.2 \%$. Về thay đổi tư thế và xoa bóp vùng tỳ đè $\geq 3$ lần/ngày chiếm tỷ lệ cao từ $87,3 \%$ đến $96.2 \%$. Kết quả cho thây, sư khác biêt có ý nghĩa thống kê giữa nhóm ngưới bênh có BMI bình thường và BMI béo phì với kết quả chăm sóc $(p<0,05)$, giữa người bệnh có bênh bị đái tháo đường và người bệnh không bị bệnh đái tháo đường với kết quả chăm sóc $(p<0,05)$, giữa người bệnh có thời gian nằm viện $>7$ ngày và $\leq 7$ ngày với kết quả chăm sóc $(p<0,05)$, giữa người bệnh có sử dụng nệm hơi và không sử dung nệm hơi với kết quả chăm sóc, $(\mathrm{p}<0,05)$. Tuy nhiển, chưa tìm thấy sự khác biệt giữa nam và nữ với với kết quả chăm sóc $p>0,0 \dot{5}$.

Tư khóa: bệnh nhân hôn mê, loét tỳ, vết loét, độ loét, chăm sóc, điều dưỡng.

\section{SUMMARY \\ SITUATION PRESSURE ULCERS AND A NUMBER OF FACTORS RELATED TO THE}

